\title{
Agricultura, população e dinâmica macroeconômica de municípios rurais: um estudo em Lagoa dos Três Cantos (RS)
}

\author{
Benedito Silva Neto ${ }^{1}$ \\ José Wnilson Figueiredo²
}

Resumo: Os municípios com menos de 20.000 habitantes do Rio Grande do Sul abrigam mais de um terço da população total do estado. A partir da hipótese de que a distribuição de renda, a população e a dinâmica da agricultura podem desempenhar um papel importante no desenvolvimento desses municípios, foi elaborado um modelo macroeconômico que permitisse analisar a influência desses fatores sobre economias locais. Simulações efetuadas com esse modelo, aplicado a um pequeno município agrícola do norte do estado (Lagoa dos Três Cantos), indicaram que uma distribuição de renda mais equânime associada a uma diversificação da produção provocariam um aumento significativo da demanda de bens e serviços destinados ao consumo interno, com efeitos benéficos sobre o desenvolvimento econômico local, enquanto que o aumento da produção agrícola destinada às exportações teria um impacto reduzido sobre a economia local. As simulações apontaram ainda que a diminuição da população, como a que ocorreu no município entre 1990 e 2002, traz efeitos altamente negativos sobre a demanda agregada. Assim, concluiu-se que políticas de apoio à manutenção do emprego na agricultura e que estimulem as atividades não-agrícolas podem desempenhar um importante papel no desenvolvimento desse tipo de município.

Palavras-chave: macroeconomia do desenvolvimento local, distribuição de renda, demanda agregada, desenvolvimento municipal, economia de municípios rurais.

\footnotetext{
${ }^{1}$ Eng. Agrônomo, doutor em Desenvolvimento Agrícola pelo INA-PG (França). E-mail: netobs@uol.com.br

${ }^{2}$ Eng. Agronômo, mestre em Modelagem Matemática pela Unijuí. E-mail: josewnilsonf@bol.com.br
} 
Agricultura, população e dinâmica macroeconômica de municípios rurais:

um estudo em Lagoa dos Três Cantos (RS)

\begin{abstract}
The municipalities with less than 20.000 inhabitants sum up more than one-third of the total population of Rio Grande do Sul state. Based on the hypothesis that the wealth distribution, population and the agricultural dynamic can perform an important role in the development of such municipalities, a macroeconomic model that would allow the analysis of the influences of the factors previously mentioned on the local that economies were elaborated. Simulations carried out with such model, applied to a small agricultural municipality in the north of the sate (Lagoa dos Tres Cantos), have indicated that a more egalitarian distribution of wealth associated with a diversification of the production would cause a significant increase of demand for goods and services destined to the internal consumption with beneficial effects on the local economy, while increase in the production destined to exports has little impact on the local economy. Simulations have also shown that the decrease in the number of the population, as the one that occurred in the municipality during 1990 and 2002, causes strongly negative effects on the related demand. Therefore, support policies with regards to the maintenance of jobs in agriculture and that stimulate non-agricultural activities can perform an important role in this sort of municipality.
\end{abstract}

Key-words: local development macroeconomics, wealth and income distribution, related demand, municipal development, rural municipals' economy.

\title{
Classificação JEL:
}

\section{Introdução}

Estudos recentes sobre a agricultura do Rio Grande do Sul indicam que o tipo de agricultura prevalecente em uma dada região, pelo seu efeito sobre a dinâmica demográfica e a distribuição de renda, condiciona fortemente o surgimento e a sustentação de atividades não-agrícolas e, conseqüentemente, o desenvolvimento municipal (SILVA NETO; FRANTZ, 2003). Além disso, segundo os mesmos autores, a maioria dos municípios desse estado com população inferior a 20.000 habitantes apresentam uma estrutura econômica bastante simples, na qual a agricultura é o setor produtivo predominante, responsabilizando-se pela quase totalidade das mercadorias vendidas ao exterior (para fora do município). Tal estrutura facilita a sua modelagem macroeconômica, a qual pode se constituir em um instrumento interessante para a discussão de políticas de desenvolvimento.

Neste trabalho procurou-se elaborar um modelo macroeconômico para analisar o papel da agricultura, da população e da distribuição de renda no desenvolvimento de municípios de economia predominantemente agrícola, denominados aqui de municípios "rurais", de forma a contribuir para a elaboração de políticas de desenvolvimento local. Este artigo está organizado em 
seis partes, além da introdução e das conclusões. Inicialmente, apresenta-se uma caracterização geral dos municípios com menos de 20.000 habitantes do Rio Grande do Sul. Na segunda parte, discute-se a estrutura matemática de um modelo que relaciona a população e a distribuição de renda com a demanda de bens e serviços de consumo corrente, os quais se assumem neste trabalho como os principais produtos das atividades não-agrícolas desse tipo de município. $\mathrm{Na}$ terceira parte, é feita a descrição da incorporação desse modelo em um modelo macroeconômico de demanda agregada. Em seguida, são discutidas algumas características do município de Lagoa dos Três Cantos, escolhido como caso a ser estudado. Na quinta parte do artigo, o modelo macroeconômico discutido na terceira parte é parametrizado a partir da situação do município de Lagoa dos Três Cantos no ano de 2002. Na sexta seção, a partir do modelo de demanda agregada parametrizado, são efetuadas simulações para a análise dos possíveis efeitos da produção agrícola, da distribuição de renda, da dinâmica demográfica e da diversificação das atividades não-agrícolas sobre o desenvolvimento econômico do município. Os resultados dessas simulações são, então, discutidos e, com base nas conclusões, elaboram-se considerações sobre políticas de desenvolvimento para municípios rurais.

\section{Municípios rurais no estado do Rio Grande do Sul}

Segundo Veiga (2001), a inexistência de critérios coerentes para a definição do que é rural e do que é urbano no Brasil transformou vilas e cidades rurais em centros urbanos. Em 70\% dos municípios brasileiros, a densidade demográfica é inferior a 40 habitantes $/ \mathrm{km}^{2}$, sendo que, segundo a OCDE (Organização para a Cooperação Econômica e o Desenvolvimento), para que uma localidade seja considerada urbana sua densidade deve ser de, no mínimo, $150 \mathrm{hab} / \mathrm{km}^{2}$. Por esse critério, apenas 411 dos 5.507 municípios brasileiros existentes no ano de 2000 seriam classificados como urbanos.

De acordo com o que é abordado por Veiga (2001), deveriam ser considerados "cidades" apenas municípios com uma população mínima entre 50.000 e 100.000 habitantes e densidade demográfica superior a $80 \mathrm{hab} / \mathrm{km}^{2}$. Os municípios que o autor denomina de "rurbanos" se caracterizam por apresentar população entre 50.000 e 100.000 habitantes ou menos, mas densidade inferior a $80 \mathrm{hab} / \mathrm{km}^{2}$. Enfim, os municípios com menos de 50.000 habitantes e densidade demográfica menor que $80 \mathrm{hab} / \mathrm{km}^{2}$ o autor classifica como "rurais".

Com base nos conceitos desenvolvidos por Veiga (2001), Silva Neto e Frantz (2003) consideraram municípios rurais no Rio Grande do Sul com menos de 20.000 habitantes, nos quais a agricultura é o setor predominante na economia. Como pode ser observado na Figura 1, a população total desses municípios, que 
representa mais de um terço da população total do estado, tem crescido ligeiramente nas últimas décadas, após um forte decréscimo entre 1970 e 1980.

Essa estabilidade da população total dos municípios rurais do Rio Grande do Sul pode ser explicada pelo vigoroso processo de criação de novos municípios, ocorrido a partir de 1981, como mostra a Figura 2.

Silva Neto e Frantz (2003) constataram que a criação de novos municípios sempre foi, ao longo da história do Rio Grande do Sul, mais intensa nas regiões de agricultura familiar. Segundo esses autores, uma distribuição de renda mais eqüitativa e uma densidade demográfica mais elevada nessas regiões originaram uma demanda de bens e serviços relativamente expressiva, responsável por um maior dinamismo das economias locais, o qual deu origem à formação de núcleos habitacionais. Com o reconhecimento desses núcleos como municípios, estes passam a receber verbas estaduais e federais que, por sua vez, proporcionam um novo impulso ao seu desenvolvimento.

Figura 1. População total dos municípios de menos de 20.000 habitantes no estado do Rio Grande do Sul, Brasil

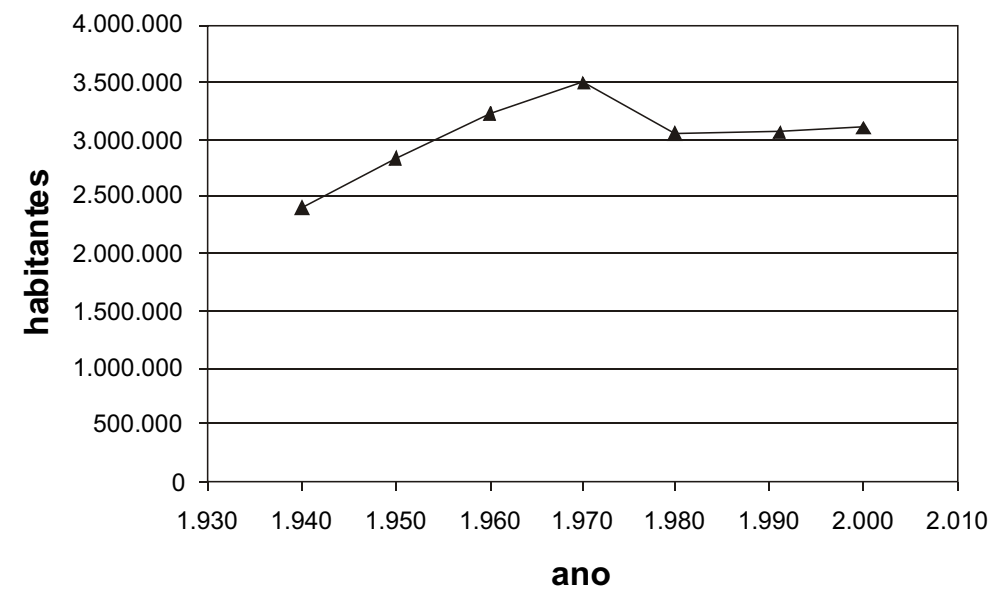

Fonte: Jardim (2001).

Por outro lado, conforme constata Santos (2004), os municípios brasileiros com menos de 30.000 habitantes são altamente dependentes de verbas federais para a sua manutenção. Segundo a autora, em 2002, o Fundo de Participação dos Municípios (recursos federais) foi responsável por quase 37\% das receitas orçamentárias dos municípios com menos de 30.000 habitantes da região Sul do Brasil (formada pelos estados do Rio Grande do Sul, Santa Catarina e Paraná). 
Figura 2. Número de municípios no estado do Rio Grande do Sul, Brasil Fonte: Jardim (2001).

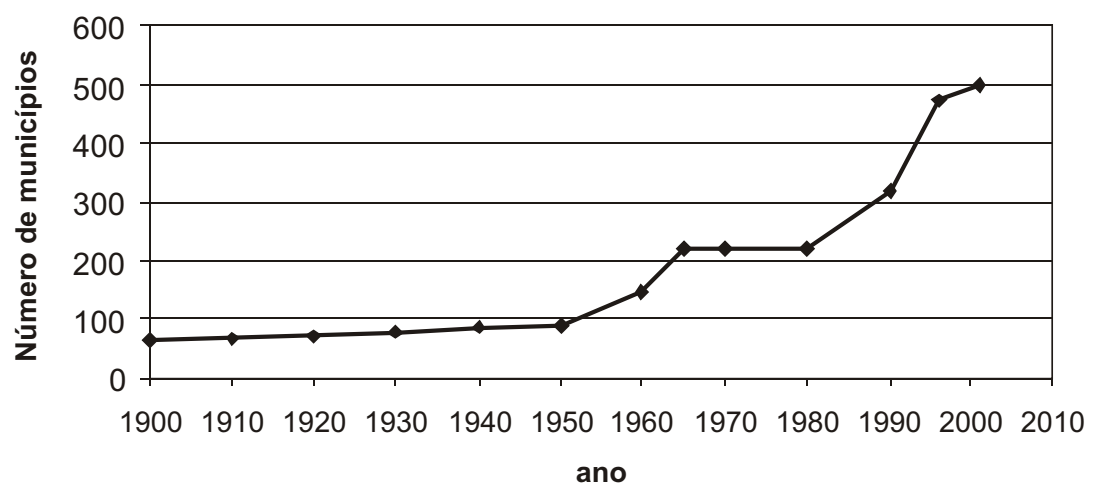

Fonte: Jardim (2001).

\section{Demanda e distribuição de renda}

Em meados do século XIX, um diretor do escritório prussiano de estatística, Ernst Engel (apud BOUSSARD, 1987), já observava que a proporção das despesas de uma família com alimentos, em relação à sua renda, diminui com o aumento do seu nível de renda, fenômeno que ficou conhecido na literatura como "Lei de Engel". Esta "lei" também é válida para bens de consumo corrente que, como os alimentos, são destinados à satisfação das necessidades básicas dos indivíduos (MOUNIER, 1992). Um dos modelos mais utilizados para descrever a demanda em função da renda é o modelo AIDS (Almost Ideal Demand System) de Deaton e Muellbauer (1980). Neste trabalho, propõe-se uma versão simplificada desse modelo para relacionar o consumo por pessoa de bens e serviços produzidos no município com o consumo total por pessoa, conforme descrito a seguir:

$$
\log C_{1}=\log a+b \log C
$$

ou

$C_{1}=a C^{b}$

em que

$C_{1}=$ consumo por pessoa de bens e serviços produzidos localmente

$a=$ coeficiente associado à distribuição de renda

$C=$ consumo total por pessoa de bens e serviços

$b=$ coeficiente associado ao tipo de bens e serviços produzidos no município 
A relação entre o valor de (a) e a distribuição de renda pode ser demonstrada considerando-se que a demanda agregada média corresponde à soma da demanda de cada um dos indivíduos do município, dividida pelo número de indivíduos. A cada uma dessas demandas, agregada e individual, corresponde uma equação com um coeficiente de distribuição de renda específico: $(a)$ e $\left(a_{i}\right)$, respectivamente. Assim,

$$
a C^{b}=\frac{\sum_{i=1}^{n} a_{i} C_{i}^{b}}{n}
$$

em que $\left(C_{i}\right)$ é o consumo de cada indivíduo do município e $(n)$, o número de indivíduos. Considerando $\left(a_{i}\right)$ o mesmo para todos os indivíduos, expressa-se o consumo por pessoa de bens e serviços locais como

$$
a C^{b}=a_{i} \frac{1}{n} \sum_{i=1}^{n} C_{i}^{b}
$$

Considerando que

$$
C^{b}=\left(\frac{\sum_{i=1}^{n} C_{i}}{n}\right)^{b}
$$

e isolando $\left(a_{i}\right)$, tem-se

$$
a_{i}=a n \frac{\left(\frac{\sum_{i=1}^{n} C_{i}}{n}\right)^{b}}{\sum_{i=1}^{n} C_{i}{ }^{b}}
$$

A partir da equação (5), analisa-se a influência da distribuição de renda sobre o consumo de bens e serviços locais por meio das relações entre $(a),\left(a_{i}\right)$ e $(b)$.

Assim, para $0<(b)<1$ (bens normais ou necessários), então $\left(a_{i}\right)>(a)$, indicando que uma distribuição de renda mais igualitária provocaria um aumento do consumo de bens e serviços locais.

Já nos casos em que $(b)<0$ (bens inferiores) ou $(b)>1$ (bens superiores, ou de luxo), então $\left(a_{i}\right)<(a)$, indicando que uma distribuição de renda mais igualitária proporcionaria uma diminuição do consumo de bens e serviços locais. Enfim, 
para $(b)=1$, a distribuição de renda não teria influência sobre o consumo de bens e serviços locais.

Para permitir que o coeficiente $\left(a_{i}\right)$ seja estimado a partir de $(a)$ e de valores de (C) obtidos segundo um determinado índice de dispersão da renda, como o Índice de Gini, efetuou-se uma adaptação da equação (5) de forma a possibilitar o cálculo de $\left(a_{i}\right)$ a partir de estratos de renda e não da renda de cada indivíduo. Assim, substituindo (4) em (5) e o consumo de cada indivíduo pelo consumo em cada estrato, tem-se:

$$
a_{i}=a n \frac{C^{b}}{\sum\left[j\left(C_{p}^{b}\right)+k\left(C_{q}{ }^{b}\right)+l\left(C_{r}^{b}\right)+m\left(C_{s}^{b}\right)\right]}
$$

em que

$j, k, l, m=$ número de indivíduos, respectivamente, nos estratos de renda $p, q, r, s$

$C_{p}, C_{q}, C_{r}, C_{s}=$ consumo por pessoa, respectivamente, nos estratos de renda $p, q, r, s$

Essa adaptação leva a uma perda de precisão na estimativa, porém algumas simulações indicaram que tal perda é pequena quando considerados dez estratos ou mais.

\section{O modelo de demanda agregada}

Nos anos 30 do século XX, Keynes evidenciou que o efeito de uma atividade sobre a economia não se restringe à renda que ela gera diretamente, mas inclui também uma renda induzida pelo efeito que a atividade em questão exerce sobre a demanda agregada (KEYNES, 1982).

Neste trabalho, foi elaborado um modelo macroeconômico de demanda agregada de municípios agrícolas a partir dos seguintes pressupostos:

- A produção agrícola corresponde a uma base exportadora para esses municípios, ou seja, a agricultura é o setor com capacidade de promover, por meio da produção, a entrada de moeda no município, visto que as vendas externas do comércio e da indústria não são significativas.

- A economia local é aberta e extrovertida, ou seja, as relações de troca se dão sem barreiras, além da distância e das condições de transporte, sendo que, portanto, os municípios próximos exercem uma influência importante sobre a economia local.

- A maior parte dos investimentos é efetuada pela compra de máquinas e equipamentos fora do município. Assim, a maioria dos gastos relativos aos investimentos não circula na economia do município, gerando uma aparente defasagem entre a poupança interna e os investimentos realizados. 
- Os impostos são proporcionais à atividade econômica local, ou seja, a arrecadação de impostos do município é proporcional às suas atividades econômicas.

- Os gastos públicos não são proporcionais à atividade econômica local. Isso ocorre pelo fato de os municípios receberem recursos estaduais e federais, independentemente do nível da sua atividade econômica.

- Existe uma disponibilidade limitada de bens e serviços de consumo produzidos no município, ou seja, o comércio local não disponibiliza todos os tipos de bens e serviços que são consumidos pela população local.

- Os bens e serviços produzidos localmente são produtos necessários, ou seja, embora seu consumo cresça com o aumento da renda, este consumo representa uma parte cada vez menor do consumo total.

Segundo o princípio de Malthus (apud SOUZA, 1999), a demanda agregada corresponde à demanda de bens e serviços para a qual existe uma capacidade de pagamento, podendo ser igual ou inferior ao nível da demanda desejada pela população, de acordo com suas necessidades. Já Brue e McConnell (2001) definem a demanda agregada como uma escala ou curva que mostra as várias quantidades de bens e de serviços, que os consumidores, empresas e o governo desejam coletivamente comprar em cada nível de preço possível. Na medida em que diminui a propensão a consumir das pessoas, das firmas ou do governo, seja pela redução da renda, alta dos impostos ou outro fator, ocorre a queda na demanda agregada. Da mesma maneira em uma economia aberta, se as exportações diminuem ou as importações aumentam, a demanda agregada diminui.

Formalmente, pode-se definir a demanda agregada, do ponto de vista da produção, como:

$Y=C+I+G+E-M$

e do ponto de vista da própria demanda, como

$Y=C+S+T$

em que

$C=$ consumo total

$I=$ investimentos internos (gastos dentro do município)

$G=$ gastos e transferências de renda do governo

$E=$ exportações

$M=$ importações

$S=$ poupança

$T=$ impostos e taxas

A demanda agregada $(Y)$ na medida em que se constitui em uma demanda efetiva, e não apenas potencial, corresponde à renda total da economia. 
O investimento interno é considerado o valor da poupança $(S)$ menos a parcela da poupança que é gasta fora do município para adquirir bens de produção $(L)$, ou seja,

$$
I=S-L
$$

ou

$$
I=S(1-L \%)
$$

em que

$$
L \%=\frac{L}{S}
$$

É importante salientar que $(L)$ não corresponde necessariamente a investimentos no exterior ou a transferências de capital, tendo em vista que, nesse modelo, $(L)$ representa principalmente a importação de bens de produção (com destaque para máquinas e equipamentos não disponíveis no município) para a manutenção ou ampliação da capacidade produtiva local.

O consumo total $(C)$ é a parte da produção utilizada para a manutenção da população, sendo determinado a partir da taxa de propensão ao consumo (c) multiplicada pela diferença entre a renda total $(Y)$ e o total dos Impostos $(T)$, considerando que o aumento destes provoca uma redução da renda total, o que se reflete na queda do consumo.

$$
\begin{aligned}
& C=c(Y-T) \\
& T=t Y
\end{aligned}
$$

em que

$t=$ taxa de impostos

A partir de (8), obtem-se $s$, dados c e $t$, ou seja,

$$
\begin{aligned}
& Y=C+S+T \\
& Y=c(Y-T)+S+T
\end{aligned}
$$

dado que

$S=s Y$

e substituindo $(T)$ conforme (13), tem-se

$$
Y=c Y-c t Y+s Y+t Y
$$


da qual, dividindo toda a expressão por ( $Y$ e alterando a ordem dos termos, obtem-se

$$
s=1-t-c(1-t)
$$

Para permitir a análise da distribuição de renda sobre o consumo de bens e serviços locais, neste trabalho foi considerado o consumo total (C) como sendo a soma do consumo de bens e serviços produzidos no município $\left(C_{1}\right)$ com o consumo de bens e serviços destinados ao consumo final adquiridos fora do município $\left(C_{2}\right)$.

$$
C=C_{1}+C_{2}
$$

O consumo de bens e serviços produzidos no município, denominado doravante de consumo local, é definido a partir do consumo total, aplicando-se a equação (1).

Na medida em que $(C)$ é definido a partir da equação $(13)$ e $\left(C_{1}\right)$ é obtido a partir de $(C),\left(C_{2}\right)$ pode ser obtido por:

$$
C_{2}=C-C_{1}
$$

A importação ( $M$ ) é o somatório de todos os bens e serviços adquiridos no exterior, ou seja, de outros municípios. Nesse modelo, $(M)$ é descrita por:

$$
M=M_{1}+M_{2}
$$

em que $\left(M_{1}\right)$ é a importação de bens e serviços destinados à produção interna e $\left(M_{2}\right)$ é a importação de bens e serviços destinados ao consumo, ou seja,

$$
M_{2}=C_{2}
$$

Como nesse modelo considera-se que o consumo local $\left(C_{1}\right)$ corresponde ao produto bruto das atividades não-agrícolas do município, $M_{1}$ pode ser obtido por

$$
M_{1}=\frac{C_{1} m_{i}}{\left(m_{i}+1\right)}
$$

em que $\left(m_{i}\right)$ é um coeficiente que expressa o valor das importações destinadas à produção de bens e serviços consumidos localmente em relação ao valor agregado por este setor, ou seja,

$$
m_{i}=\frac{M_{1}}{\left(C_{1}-M_{1}\right)}
$$

A partir de $(Y),\left(M_{1}\right)$ e $\left(M_{2}\right)$, pode-se definir um coeficiente global de importação, ou seja, 


$$
m=\frac{M}{Y} \quad \text { ou } \quad M=m Y
$$

Com as exportações $(E)$, os gastos públicos $(G)$ e o Investimento Interno $(I)$, assim como com o coeficiente global de importação $(m)$ e das taxas de impostos $(t)$ e de poupança (s), define-se a renda total $(Y)$. Assim, a partir da igualdade entre (7) e (8), substituindo $(T),(S)$ e $(M)$ respectivamente pelas equações (13), (14) e (23), tem-se:

$$
C+I+G+E-m Y=C+t Y+s Y
$$

da qual pode-se deduzir que

$$
Y=\frac{G+E+I}{(m+t+s)}
$$

Assim, nesse modelo, a renda é determinada por

$$
Y=k(G+E+I)
$$

em que ( $k$ ) é o multiplicador keynesiano, ou seja,

$$
k=\frac{1}{m+t+s}
$$

O efeito multiplicador parte da premissa de que o importante na determinação da renda em uma economia não corresponde apenas à soma dos investimentos, dos gastos públicos e do consumo privado, mas também aos efeitos que estes acarretam na economia, os quais estão relacionados aos coeficientes de importação e às taxas de impostos e de poupança. A partir desse indicador, obtém-se a demanda gerada por unidade monetária gasta no município.

No entanto, nesse modelo, o multiplicador $(k)$ não é constante em relação à renda total $(Y)$. A variação do multiplicador frente à renda total pode ser explicada pela variação do coeficiente global de importação $(m)$, o qual aumenta com o crescimento da renda total, na ausência de mudanças na economia que levem à alteração dos coeficientes $(a)$ e $(b)$ da equação $(1)$, a qual relaciona a parcela da renda detida pelos consumidores $(C)$, com a parcela desta renda que é consumida em bens e serviços locais $\left(C_{1}\right)$. Assim, a partir das equações (19) e (23), tem-se:

$$
m=\frac{M_{1}+M_{2}}{Y}
$$

Substituindo $\left(M_{1}\right)$ e $\left(M_{2}\right)$, respectivamente, pelas equações (21) e (18), tem-se: 


$$
m=\frac{\frac{C_{1} m_{i}}{\left(m_{i}+1\right)}+\left(C-C_{1}\right)}{Y}
$$

ou seja,

$$
m=\frac{C_{1}\left(\frac{m_{i}}{\left(m_{i}+1\right)}-1\right)+C}{Y}
$$

\section{Como}

$$
\frac{m_{i}}{\left(m_{i}+1\right)}-1<0
$$

considera-se

$$
\frac{m_{i}}{\left(m_{i}+1\right)}-1=-\beta
$$

que, substituindo em (30), obtém-se

$$
m=\frac{C-\beta C_{1}}{Y}
$$

Considerando que $0<(b)<1$, com o aumento de $(Y),\left(m_{i}\right)$ e, portanto, $(\beta)$ permanecendo constantes, $(C)$ aumenta mais rápido que $\left(C_{1}\right)$, fazendo com que $\left(C-\beta C_{1}\right)$ aumente mais rapidamente que $(Y)$, do que resulta a alta do valor de $(m)$. Com a elevação de $(m)$, de acordo com a equação $(27),(k)$ diminui.

O modelo também define o saldo da balança comercial, correspondente à diferença entre as exportações e as importações $(E-M)$, o saldo das contas públicas, correspondente à diferença entre os gastos públicos e os impostos arrecadados $(G-T)$ e o saldo correspondente à diferença entre poupança e investimento $(S-I)$, denominado aqui de saldo da conta de capital. A partir desses três saldos, foi definido um balanço global de pagamentos, o qual deve ser nulo, ou seja,

$$
I+G+E=T+S+M
$$

O balanço global de pagamentos, que deve ser nulo, significa que a retirada de moeda de circulação, seja pela sua saída do município por meio de importações ou impostos estaduais e federais, seja pelo seu entesouramento por meio da poupança ou impostos municipais, deve estar sempre em equilíbrio com a entrada de moeda em circulação no município por meio de gastos públicos, exportações ou 
investimentos. Ressalta-se que, nesse modelo, o saldo positivo das contas de capital $(S-I)$ não significa acumulação de moeda (entesouramento), enquanto o saldo da balança comercial $(E-M)$ e o saldo das contas públicas $(G-T)$ - este último viabilizado pelos recursos públicos recebidos dos governos federal e estadual permitem ao município adquirir bens de produção de fora da sua economia.

\section{O município de Lagoa dos Três Cantos}

O município de Lagoa dos Três Cantos está localizado na região norte do estado do Rio Grande do Sul, a 226 quilômetros da capital Porto Alegre, e possui uma área territorial de $135,8 \mathrm{Km}^{2}$. Foi emancipado no ano de 1992, sendo anteriormente um distrito do município de Tapera. Em 2000, a população era de 1.627 pessoas, das quais 952 estavam na zona rural e 675 habitavam na zona urbana (IBGE, 2000).

Em Lagoa dos Três Cantos, o setor industrial tem uma participação reduzida na economia local - dados de 1993 indicam a existência de nove estabelecimentos industriais. O comércio também é bastante incipiente, com o município dispondo de apenas 15 estabelecimentos comerciais, dois quais 11 se dedicam à atividade comercial do varejo e quatro, ao ramo atacadista. O setor primário predomina em relação aos outros setores da economia local, com 372 estabelecimentos agrícolas (IBGE, 2000). Esse número representa 93,9\% do total de estabelecimentos dos setores produtivos de Lagoa dos Três Cantos, que, portanto, pode ser considerado um município de economia predominantemente agrícola (município rural), respondendo pelo maior número de empregos e pelo maior valor agregado.

Já a indústria e o comércio têm uma pequena participação na atividade econômica de Lagoa dos Três Cantos, com o percentual de estabelecimentos desses setores se situando na faixa de $6 \%$, sendo, assim, responsáveis por um valor agregado bastante reduzido quando comparados com o setor primário.

O surgimento do município de Lagoa dos Três Cantos está ligado ao fluxo de imigrantes de origem européia (alemães e italianos, principalmente) que, a partir de 1824, se estabelecem nas regiões próximas a Porto Alegre e, após 1890, passam a ocupar o norte e o noroeste do estado. Tal ocupação foi estabelecida inicialmente pelo estado e, após 1924, foi predominada por companhias privadas de colonização, das quais os colonos adquiriam lotes de terra de 25 hectares, dando origem a uma agricultura tipicamente familiar.

A partir dos anos 60 e, principalmente, depois de 1972, as técnicas baseadas em insumos e equipamentos de origem industrial se generalizam, consolidando a acumulação de capital de parte dos agricultores (SILVA NETO; BASSO, 2005). Nesse período, a rápida industrialização do País, ao criar empregos urbanos, faz com que as cidades exerçam uma forte atração sobre agricultores menos 
- Agricultura, população e dinâmica macroeconômica de municípios rurais: um estudo em Lagoa dos Três Cantos (RS)

capitalizados, muitos dos quais vendem suas terras para tentar a sorte no meio urbano (SILVA NETO; BASSO, 2005).

Apesar de ter tido um forte arrefecimento a partir dos anos 80, especialmente no que se refere à criação de empregos urbanos, esse processo permite compreender os dados dos últimos censos demográficos, que mostram uma diminuição da população de Lagoa dos Três Cantos, a qual passou de 1.789 habitantes em 1993 para 1.553 em 2004 (IPD, 2005).

Em relação à estrutura fundiária, em 1995 o município contava com 372 estabelecimentos agrícolas e uma área cultivável de 10.780 hectares, resultando em uma média de 28,98 hectares por unidade de produção (IBGE, 2000). Pelos dados do Censo Agropecuário de 1995, apesar de ainda contar com aproximadamente $20 \%$ dos estabelecimentos com menos de 10 hectares, existe uma predominância de médias propriedades (entre 20 e 100 hectares), as quais representam $58 \%$ do total dos estabelecimentos.

Na produção agrícola de Lagoa dos Três Cantos, a agricultura comercial se apresenta em maior escala, embora a cultura de subsistência também seja importante. Comercialmente, a produção de soja se sobressai, sendo que, na pecuária, o destaque vai para leite, suínos e aves. Junto à produção de soja, aparece a de milho no verão e, no inverno, a cultura do trigo, da cevada e, em menor escala, a aveia para grão, além das pastagens anuais e perenes para alimentação do gado leiteiro. A produção leiteira é praticada de forma intensiva, observando-se maior número de animais de raças leiteiras puras (FIGUEIREDO, 2005).

Em algumas propriedades destacam-se as produções de suínos terminados com produtores integrados e não-integrados, enquanto em outros estabelecimentos agrícolas prevalece a produção de frango em sistema de integração. Quanto ao grau de mecanização, o município apresenta, na maioria das propriedades, mecanização completa ou associações de produtores com a finalidade de aquisição e uso de máquinas. Em Lagoa dos Três Cantos, se sobressai a categoria social dos agricultores familiares, aparecendo também minifúndios e patronais.

Segundo dados do Ipea (Instituto de Pesquisa Econômica Aplicada), em 2000 o Índice de Desenvolvimento Humano Municipal (IDH-M) de Lagoa dos Três Cantos foi de 0,838 , considerado elevado para os padrões brasileiros. Em relação a 1991, quando o índice foi de 0,774, houve aumento de 8,27\%. Assim, dos 5.517 municípios existentes em 2000, apenas 77 (1,4\%) apresentavam um IDH superior ao de Lagoa dos Três Cantos. A dimensão que mais contribuiu para o crescimento do índice foi a renda, com 42,2\%, seguida pela educação, com 33,9\%, e pela longevidade, com $24 \%$. Nesse período, o hiato de desenvolvimento humano (a distância entre o IDH do município e o limite máximo do IDH, ou seja, 1- IDH) foi reduzido em $28,3 \%$. 
Ainda conforme o Ipea (2003), a renda mensal média por pessoa do município cresceu 62,95\%, passando de $\mathrm{R} \$ 215,89$ em 1991 para $\mathrm{R} \$ 351,80$ em 2000. A pobreza (medida pela proporção de pessoas com renda domiciliar inferior a $\mathrm{R} \$ 75,50$, equivalente à metade do salário mínimo vigente em agosto de 2000) diminuiu 59,19\%, passando de 30,4\% em 1991 para 12,4\% em 2000. A desigualdade na distribuição de renda também reduziu, com o Índice de Gini para a renda passando de 0,57 em 1991 para 0,52 em 2000.

\section{Parametrização do modelo}

O modelo de demanda agregada descrito anteriormente foi parametrizado a partir de informações reunidas por Figueiredo (2005) junto à Prefeitura Municipal de Lagoa dos Três Cantos (RS), à Secretaria da Fazenda Estadual, à Receita Federal e ao escritório do INSS, além de dados do IBGE (Instituto Brasileiro de Geografia e Estatística). Utilizou-se como ano base o de 2002, por ser o ano mais recente com informações referentes ao valor adicionado.

Os dados relacionados à renda total $(Y)$ foram obtidos a partir do relatório do valor adicionado por atividade econômica fornecido pela Secretaria da Fazenda do estado. O valor adicionado total do município de Lagoa dos Três Cantos, em 2002, foi de R\$18,1 milhões.

Para estimar o valor das exportações, consideraram-se as produções de trigo e soja e $86 \%$ da de leite - isso baseado no fato de que em Lagoa dos Três Cantos não existem unidades de beneficiamento de trigo e soja e o consumo da produção local desses produtos é insignificante. Conforme critério adotado por Calegaro (2004) em estudo semelhante, o consumo de subsistência, no caso do leite, foi assumido como $14 \%$ do total da produção. Dessa maneira, obteve-se um produto bruto das exportações da ordem de $\mathrm{R} \$ 24,34$ milhões.

A partir da análise econômica dos sistemas de produção dos tipos de agricultores de Lagoa dos Três Cantos, estimou-se o valor agregado correspondente a cerca de $50 \%$ do produto bruto, com pequenas variações entre os tipos (FIGUEIREDO, 2005). Com esses resultados, o valor agregado das exportações foi estimado em $\mathrm{R} \$ 12,17$ milhões.

Para se chegar aos valores referentes às contas públicas foram considerados os gastos públicos e a arrecadação do município gaúcho, segundo Figueiredo (2005).

Ao analisar os dados da Tabela 1, nota-se um desequilíbrio entre receitas e despesas públicas, com os Gastos e Transferências Públicos $(G)$ equivalendo a R\$ 4.053.811,00 e a arrecadação de impostos $(T)$, a $R \$ 929.566,00$. Isso significa que a renda recebida do exterior representa um importante ingresso líquido de moeda em Lagoa dos Três Cantos. 
Agricultura, população e dinâmica macroeconômica de municípios rurais: um estudo em Lagoa dos Três Cantos (RS)

Tabela 1. Arrecadação e gastos públicos em Lagoa dos Três Cantos - 2002

\begin{tabular}{lcc}
\hline Discriminação & Arrecadação (R\$) & Gastos (R\$) \\
\hline Município & 446.270 & 446.270 \\
Estado & 120.919 & $(1) 874.921$ \\
União & 89.061 & $(2) 1.905 .202$ \\
INSS & 273.316 & $(3) 827.418$ \\
Total & 929.566 & 4.053 .811
\end{tabular}

(1) Inclui repasses do estado. (2) Inclui repasses da União. (3) Inclui aposentadorias.

Fonte: Figueiredo (2005).

Essa renda é transferida ao município via repasses estaduais e federais. Os repasses estaduais correspondem às cotas-parte do imposto sobre a circulação de mercadorias e serviços (ICMS), do imposto sobre a propriedade de veículos automotores (IPVA) e do imposto sobre produtos industriais (IPI). Já os repasses federais são realizados por meio do Fundo de Participação dos Municípios (FPM) e pelo pagamento de aposentadorias a pessoas residentes no município.

O coeficiente de importação $\left(m_{i}\right)$ foi considerado igual a 2 devido à predominância do comércio nas atividades não-agrícolas do município. Criou-se um coeficiente que expressa a proporção da poupança interna que é destinada à aquisição de bens de produção no exterior do município, sendo o restante gasto com bens de produção - especialmente ferramentas e equipamentos simples adquiridos internamente. Esse coeficiente foi estimado juntamente com o coeficiente de consumo, procurando-se mantê-los a valores próximos de $90 \%$ e $75 \%$, respectivamente. Assim, efetuando-se os ajustes necessários para manter a coerência do modelo, indicada pelo balanço global nulo, o coeficiente que expressa a poupança destinada ao exterior foi fixado em $88 \%$ e o de consumo global, em $74 \%$.

Uma pesquisa de campo foi realizada no município para estimar o coeficiente de distribuição de renda agregado (a) e o coeficiente associado ao tipo de bem e serviço $(b)$. Calculou-se uma amostra pelo método de estimativas de proporções intervalares (STEVENSON, 1981).

Como parâmetros para a obtenção do tamanho da amostra foram considerados uma proporção entre consumo local e consumo total de bens e serviços hipotética de $30 \%$, um erro de estimação de $5 \%$ e o tamanho da população do município, os quais, por meio de

$$
n=\frac{z^{2} p(1-p) N}{(N-1) e^{2}+z^{2} p(1-p)}
$$

em que

$n=$ tamanho da amostra

$z=$ variável reduzida da distribuição normal 
$p=$ proporção amostral

$N=$ tamanho da população

$e=$ erro de estimação

resultaram em uma amostra de 190 pessoas. Tal amostra foi, então, dividida em 10 estratos de renda de acordo com o coeficiente de Gini calculado para o município de Lagoa dos Três Cantos pelo Ipea (2002).

No trabalho de campo, os entrevistados responderam a um questionário que versava sobre a sua renda e a composição do seu consumo de bens e serviços, englobando a origem de compra desses itens. Os dados obtidos foram, então, agregados para a discriminação do consumo de bens e serviços adquiridos dentro e fora do município. Para a análise de regressão entre esses dois conjuntos de dados, foi feito um ajuste linear da função potência que descreve a relação existente entre consumo local e total. Assim, a partir da equação (1), na sua forma logarítmica,

$$
\ln C_{1}=\ln a+b \ln C
$$

foram definidas as variáveis $(X)$ e $(Z)$,

$$
X=u+b Z, \text { em que } u=\ln a \text { e } Z=\ln C
$$

Foi efetuada uma regressão linear pelo método dos quadrados mínimos (Bassanezi, 2002), a qual forneceu a equação

$$
X=1,4332+0,7203 Z
$$

O coeficiente de determinação (R-Quadrado) obtido foi de 0,56383 , sendo que o teste $\mathrm{F}$ indicou uma significância de $1 \%$.

Considerando que

$$
u=1,4332 \Rightarrow a_{i}=e^{1,4332}=4,1920
$$

A partir de $\left(a_{i}\right)$, pode-se, então, obter $(a)$ por meio da equação (6), resultando no valor de 3,89672769 .

Assim, a equação da função potência ajustada que modela a relação entre o consumo local $\left(C_{1}\right)$ e o consumo total $(C)$, para o município de Lagoa dos Três Cantos, é

$$
C_{1}=3,89672769 C^{0,7203}
$$


Agricultura, população e dinâmica macroeconômica de municípios rurais:

um estudo em Lagoa dos Três Cantos (RS)

Figura 3. Comportamento do consumo local em função do consumo total no município de Lagoa dos Três Cantos

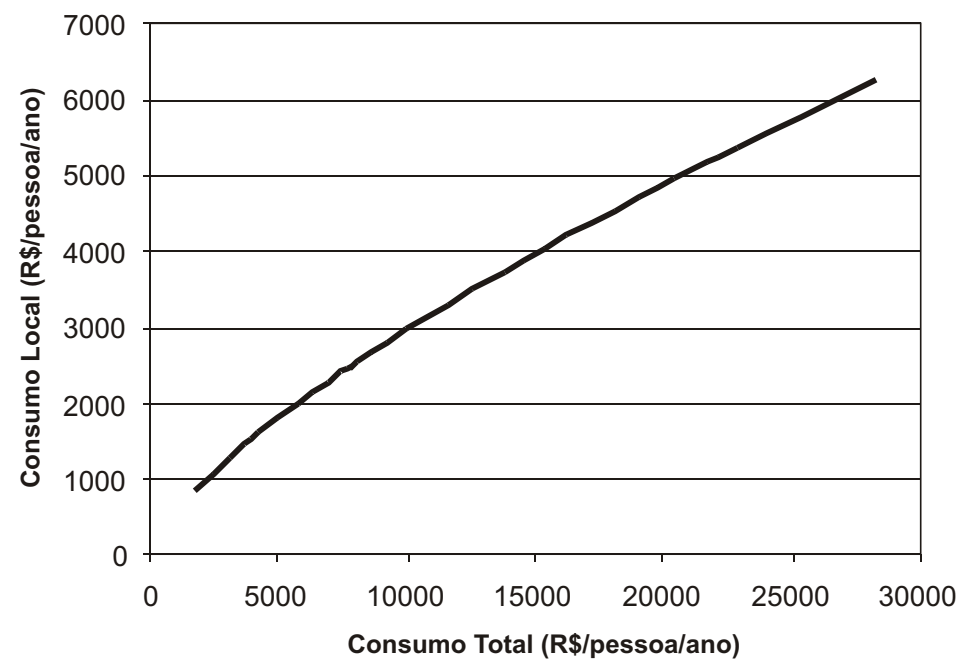

Fonte: Figueiredo (2005).

Observando-se os valores encontrados para o coeficiente de distribuição de renda individual $\left(a_{i}=4,1920\right)$, para o coeficiente de distribuição de renda agregado $(a=3,89672769)$ e para o coeficiente associado ao tipo e disponibilidade de bens e serviços de consumo produzido no município $(b=0,7203)$, é possível afirmar que uma distribuição de renda mais igualitária provocaria um aumento no consumo local de bens e serviços em Lagoa dos Três Cantos. Isso porque o coeficiente ai é menor que o coeficiente $a$, e o valor do coeficiente associado ao tipo de bem e serviço encontra-se no intervalo entre 0 e 1 .

A partir da População, Produto Total, Gastos Públicos, Impostos, Exportações e dos coeficientes de importação de bens de produção $\left(m_{i}\right)$, de distribuição de renda (a) e de tipo de bens e serviços $(b)$, os valores dos demais coeficientes foram ajustados utilizando-se uma planilha do programa Excel (Microsoft inc., 1998).

\section{Resultados e Discussão}

O modelo parametrizado é apresentado na Tabela 2. Conforme se pode observar, a renda induzida pelos gastos provenientes da entrada de moeda em Lagoa dos Três Cantos por meio das exportações, dos gastos públicos e dos investimentos internos é bastante baixa, como indicado pelo multiplicador $(k)$, segundo o qual a circulação da moeda introduzida no município gera apenas $8 \%$ a mais de renda. Tal valor é explicado pelo elevado coeficiente global de importações $(m)$. Outro aspecto interessante da economia de Lagoa dos Três 
Cantos, mostrado na Tabela 2, é que a proporção do consumo local em relação ao consumo total é bastante baixa, de apenas $31,82 \%$, o que atesta o pequeno desenvolvimento das atividades econômicas do município orientadas para a produção de bens e serviços para o consumo local.

Tabela 2. Modelo macroeconômico parametrizado de Lagoa dos Três Cantos (RS).

\begin{tabular}{|c|c|c|c|}
\hline Parâmetro & Unidade & Fórmula & Valor \\
\hline População & pessoas & $P=$ & 1629 \\
\hline Produto Total & $\mathrm{R} \$$ & $Y=C+I+G+E-M$ & 18.100 .000 \\
\hline Gastos Públicos & $\mathrm{R} \$$ & $G=$ & 4.050 .000 \\
\hline Investimentos & $\mathrm{R} \$$ & $I=Y^{*} S^{*}(1-L \%)$ & 537.606 \\
\hline Exportações & $\mathrm{R} \$$ & $E=$ & 12.170 .000 \\
\hline Impostos & $\mathrm{R} \$$ & $T=t Y$ & 930.000 \\
\hline Consumo total & $\mathrm{R} \$$ & $C=Y_{c}(1-t)$ & 12.654 .285 \\
\hline Consumo total por pessoa & $\mathrm{R} \$ /$ pessoa & $C$ por pessoa $=C / P$ & 7768,131026 \\
\hline Coeficiente distribuição de renda & adimensional & $a=$ & 3,89672769 \\
\hline Coef. tipo de bens produzidos & adimensional & $b=$ & 0,720347572 \\
\hline Consumo local por pessoa & $\mathrm{R} \$ /$ pessoa & $C_{1} /$ pessoa $=a^{*}(C / P)^{b}$ & 2472,180247 \\
\hline Consumo local & $\mathrm{R} \$$ & $C_{1}=C_{1}$ por pessoa $* P$ & 4.027.182 \\
\hline Consumo local em relação ao total & adimensional & $C_{1} / C \%$ & $31,82 \%$ \\
\hline Poupança & $\mathrm{R} \$$ & $S=Y_{S}$ & 4.515 .715 \\
\hline Importações bens produção & $\mathrm{R} \$$ & $M_{1}=m_{i}^{*} C_{1} /\left(m_{i}+1\right)$ & 2.684 .788 \\
\hline Importações bens consumo & $\mathrm{R} \$$ & $M_{2}=C-C_{1}$ & 8.627.104 \\
\hline Importação Total & $\mathrm{R} \$$ & $M=M_{1}+M_{2}$ & 11.311 .892 \\
\hline Saldo Bruto Balança Comercial & $\mathrm{R} \$$ & $E-M$ & 858.108 \\
\hline Saldo das Contas Públicas & $\mathrm{R} \$$ & $G-T$ & 3.120 .000 \\
\hline Saldo Bruto da Conta de Capital & $\mathrm{R} \$$ & $S-I$ & 3.978 .108 \\
\hline Taxa de poupança transf. exterior & adimensional & $L \%=$ & 0,880947717 \\
\hline Coeficiente de poupança & adimensional & $s=1-t-c^{*}(1-t)$ & 0,249486992 \\
\hline Coeficiente de impostos & adimensional & $t=$ & 0,051381215 \\
\hline Coef. de imp. de bens de consumo & adimensional & $m_{i}=$ & 2 \\
\hline Coef. global de importações & adimensional & $m=M / Y$ & 0,624966385 \\
\hline Coeficiente de consumo & adimensional & $c=$ & 0,736999735 \\
\hline Multiplicador & adimensional & $k=1 /(m+t+s)$ & 1,080106542 \\
\hline Balanço Global & $\mathrm{R} \$$ & $(G-T)-(S-I)+(E-M)$ & 0,00 \\
\hline
\end{tabular}

Fonte: Dados de pesquisa.

Os dados da Tabela 2 reforçam a grande dependência de Lagoa dos Três Cantos em relação aos gastos públicos (principalmente verbas federais e aposentadorias), já apontada na Tabela 1, o que permite que o município, apesar do baixo saldo da balança comercial, ainda acumule poupança para adquirir bens de produção no exterior. 
Agricultura, população e dinâmica macroeconômica de municípios rurais:

um estudo em Lagoa dos Três Cantos (RS)

O modelo parametrizado descrito na Tabela 2 foi utilizado para a realização de simulações que analisassem os efeitos sobre a economia do município. Por meio de uma planilha do programa Excel (MICROSOFT INC., 1998), foram efetuadas as seguintes simulações:

a) do aumento de $R \$ 1$ milhão das exportações;

b) da diminuição de 500 pessoas na população do município;

c) do aumento das exportações de $\mathrm{R} \$ 1$ milhão e da diminuição da população ajustada de forma que o consumo local se mantivesse no mesmo nível que o observado nas condições iniciais;

d) da distribuição de renda que tornasse homogêneo os gastos com consumo de todos os indivíduos da população;

e) da diversificação da produção local de bens e serviços que permitisse elevar o consumo local a $50 \%$ do consumo total.

f) do aumento das exportações de R\$ 1 milhão e de uma diminuição da população ajustada de forma que neutralize o aumento da renda total induzida.

Os resultados das simulações correspondentes aos itens " $a$ " e " $b$ " estão na Tabela 3. Pode-se observar que um aumento das exportações de R 1 milhão provocaria uma alta induzida (correspondente ao aumento total menos o aumento das próprias exportações) de apenas $\mathrm{R} \$ 90.142$ na renda total.

Tabela 3. Simulação do efeito do aumento das exportações e da diminuição da população sobre a economia de Lagoa dos Três Cantos

\begin{tabular}{lrrr}
\hline & Condição Inicial & $\begin{array}{r}\text { Aumento das } \\
\text { exportações }\end{array}$ & $\begin{array}{r}\text { Diminuição } \\
\text { da População }\end{array}$ \\
\hline População & 1.629 & 1629 & 1129 \\
Produto Total & 18.100 .000 & 19.190 .142 & 17.958 .122 \\
Gastos Públicos & 4.050 .000 & 4.050 .000 & 4.050 .000 \\
Investimentos & 537.606 & 569.986 & 533.392 \\
Exportações & 12.170 .000 & 13.170 .000 & 12.170 .000 \\
Impostos & 930.000 & 986.013 & 922.710 \\
Consumo total & 12.654 .285 & 13.416 .438 & 12.555 .094 \\
Consumo local & 4.027 .182 & 4.200 .469 & 3.614 .191 \\
Consumo local em relação ao total & $31,82 \%$ & $31,31 \%$ & $28,79 \%$ \\
Consumo total por pessoa & 7.768 & 8.236 & 11.121 \\
Consumo local por pessoa & 2.472 & 2.579 & 3.201 \\
Coef. de distribuição de renda & 3,89672769 & 3,89672769 & 3,89672769 \\
Coef. tipo de bens produzidos & 0,720347572 & 0,72034757 & 0,72034757 \\
Poupança & 4.515 .715 & 4.787 .691 & 4.480 .318 \\
Importações de bens de produção & 2.684 .788 & 2.800 .313 & 2.409 .460 \\
\hline
\end{tabular}


Tabela 3. Continuação.

\begin{tabular}{lrrr}
\hline & Condição Inicial & $\begin{array}{r}\text { Aumento das } \\
\text { exportações }\end{array}$ & $\begin{array}{r}\text { Diminuição } \\
\text { da População }\end{array}$ \\
\hline Importações de bens de consumo & 8.627 .104 & 9.215 .969 & 8.940 .904 \\
Importação total & 11.311 .892 & 12.016 .282 & 11.350 .364 \\
Saldo balança comercial & 858.108 & 1.153 .718 & 819.636 \\
Saldo das contas públicas & 3.120 .000 & 3.063 .987 & 3.127 .290 \\
Saldo da conta de capital & 3.978 .108 & 4.217 .705 & 3.946 .926 \\
Balanço global & 0,00 & 0,00 & 0,00 \\
Coeficiente global de importações & 0,624966385 & 0,62616952 & 0,63204626 \\
Multiplicador & 1,080106542 & 1,07870474 & 1,07190963 \\
\hline
\end{tabular}

Fonte: Simulação com dados da pesquisa.

Isso se reflete no pequeno aumento do consumo local, de $\mathrm{R} \$ 173.287,00$, apesar de o consumo total registrar uma alta expressiva, de R \$762.153,00 (a qual é da mesma ordem de grandeza do aumento das exportações). Segundo os resultados apresentados na Tabela 3, o aumento das exportações também provocaria uma pequena diminuição da proporção do consumo local em relação ao consumo total, de $0,52 \%$. Observa-se ainda que uma diminuição da população em 500 pessoas provocaria uma redução na renda total do município de R\$ $141.878,00$, sendo que a diminuição no consumo total seria de R\$99.191,00; já o consumo local teria uma queda acentuada, de R $\$ 412.991,00$, ou seja, mais que o dobro da queda da renda total ou do quádruplo do consumo total, diminuindo em 3,03\% a sua participação no consumo total da população.

Na Tabela 4, encontram-se os resultados das simulações correspondentes ao aumento das exportações concomitante com a diminuição da população ajustada de modo que o consumo local se mantenha no mesmo valor da condição inicial, bem como o aumento das exportações concomitante com a diminuição da população ajustada de maneira que se neutralize o aumento da renda total induzida (itens c e f descritos anteriormente). Os dados indicam que uma diminuição de 217 pessoas seria suficiente para neutralizar o aumento do consumo local provocado por um incremento de R \$ 1 milhão nas exportações e que uma redução da população em 320 pessoas seria suficiente para neutralizar o aumento da renda induzida provocado pelo incremento das exportações de R $\$ 1$ milhão.

É interessante observar que os resultados obtidos neste trabalho, que atestam os efeitos limitados da produção agrícola sobre as atividades não-agrícolas, estão de acordo com a posição defendida pelos autores que observam haver certa dicotomia entre desenvolvimento agrícola e desenvolvimento rural (ver, por exemplo, GRAZIANO DA SILVA, 2000). De acordo com os resultados da simulação mostrados na Tabela 4, tal dicotomia pode ser explicada pelo fato de o estímulo provocado pelo aumento da produção agrícola vendida para fora do município sobre as atividades não-agrícolas locais poder ser neutralizado 
quando esse aumento é acompanhado por uma diminuição da oferta de empregos na agricultura. Essa dicotomia pode mesmo tornar-se um verdadeiro antagonismo na medida em que o atual padrão de desenvolvimento dominante na agricultura contemporânea tem levado a uma maior concentração da renda e a uma forte diminuição da população no meio rural (MAZOYER, 2001), o que tem ocorrido inclusive no município de Lagoa dos Três Cantos (FIGUEIREDO, 2005). Assim, os resultados aqui obtidos podem contribuir para explicar o maior dinamismo do desenvolvimento rural nas regiões onde a agricultura permitiu a manutenção de uma densidade demográfica mais elevada, como indicado por Silva Neto e Frantz (2003) para algumas regiões do estado do Rio Grande do Sul.

Tabela 4. Simulação do efeito do aumento concomitante das exportações e da diminuição da população sobre a economia de Lagoa dos Três Cantos

\begin{tabular}{|c|c|c|c|}
\hline & $\begin{array}{r}\text { Condiçãoo } \\
\text { Inicial }\end{array}$ & $\begin{array}{r}\text { Aumento das } \\
\text { exportações e } \\
\text { diminuição da } \\
\text { população I } \\
\end{array}$ & $\begin{array}{r}\text { Aumento das } \\
\text { exportações e } \\
\text { diminuição da } \\
\text { população II }\end{array}$ \\
\hline População & 1.629 & 1412 & 1309 \\
\hline Produto Total & 18.100 .000 & 19.130.611 & 19.100 .000 \\
\hline Gastos Públicos & 4.050 .000 & 4.050 .000 & 4.050 .000 \\
\hline Investimentos & 537.606 & 568.217 & 567.308 \\
\hline Exportações & 12.170 .000 & 13.170 .000 & 13.170 .000 \\
\hline Impostos & 930.000 & 982.954 & 981.381 \\
\hline Consumo total & 12.654 .285 & 13.374 .818 & 13.353.417 \\
\hline Consumo local & 4.027.182 & 4.027.181 & 3.938 .076 \\
\hline Consumo local em relação ao total & $31,82 \%$ & $30,11 \%$ & $29,49 \%$ \\
\hline Consumo total por pessoa & 7.768 & 9.469 & 10.199 \\
\hline Consumo local por pessoa & 2.472 & 2.851 & 3.008 \\
\hline Coeficiente de distribuição de renda & 3,89672769 & 3,89672769 & 3,89672769 \\
\hline Coeficiente tipo de bens produzidos & 0,720347572 & 0,720347572 & 0,720347572 \\
\hline Poupança & 4.515 .715 & 4.772 .839 & 4.765 .202 \\
\hline Importações de bens de produção & 2.684 .788 & 2.684 .788 & 2.625 .384 \\
\hline Importações de bens de consumo & 8.627.104 & 9.347 .637 & 9.415 .342 \\
\hline Importação total & 11.311 .892 & 12.032 .425 & 12.040 .725 \\
\hline Saldo balança comercial & 858.108 & 1.137.575 & 1.129 .275 \\
\hline Saldo das contas públicas & 3.120 .000 & 3.067 .046 & 3.068 .619 \\
\hline Saldo da conta de capital & 3.978 .108 & 4.204 .621 & 4.197 .893 \\
\hline Balanço global & 0,00 & 0,00 & 0,00 \\
\hline Coeficiente global de importações & 0,624966385 & 0,628961855 & 0,630404469 \\
\hline Multiplicador & 1,080106542 & 1,075465335 & 1,073799356 \\
\hline
\end{tabular}

Fonte: Simulação com dados de pesquisa. 
Os resultados das simulações, correspondentes a uma distribuição de renda que torne homogêneo os gastos com consumo de todos os indivíduos da população e a uma diversificação da produção local de bens e serviços de consumo corrente que possibilite elevar o consumo local a $50 \%$ do consumo total, são mostrados na Tabela 5. Os dados indicam que uma distribuição de renda no município de Lagoa dos Três Cantos, isoladamente, teria um efeito bastante limitado tanto sobre a renda total como sobre o consumo total, os quais aumentariam, respectivamente, em $\mathrm{R} \$ 111.166,00$ e $\mathrm{R} \$ 77.720,00$. Já sobre o consumo local, o efeito de uma distribuição de renda, embora também limitado, seria mais expressivo, de $\mathrm{R} \$ 323.593,00$. Tais resultados podem ser explicados pelo fato de Lagoa dos Três Cantos não apresentar uma alta concentração de renda, como indica o seu índice de Gini para a renda de 0,52 (IPEA, 2003).

Na Tabela 5, são mostrados os efeitos de uma diversificação da produção local de bens e serviços que permitisse elevar o consumo local a cerca de $50 \%$ do consumo total. Essa diversificação se expressa pela alteração do coeficiente $(b)$ da equação (1), que relaciona o consumo total e o local. Como observado na Tabela 5, tal diversificação provocaria uma elevação na renda total, de $\mathrm{R} \$ 897.937,00$, e no consumo total, de $\mathrm{R} \$ 627.776$. Já o consumo local se elevaria em $\mathrm{R} \$ 2.613 .800,00$, representado um aumento de quase $65 \%$ em relação às condições iniciais.

É interessante salientar que a diversificação da produção local de bens e serviços simulada teve um impacto positivo sobre o multiplicador, com a moeda introduzida no município passando a gerar uma renda induzida de $13 \%$, contra $8 \%$ nas condições iniciais. Tal aumento do efeito multiplicador é decorrente da queda relativa das importações, a qual se reflete na diminuição do coeficiente global de importações.

Tabela 5. Simulação do efeito de uma distribuição eqüitativa da renda e de uma diversificação da produção local sobre a economia de Lagoa dos Três Cantos

\begin{tabular}{lrrr}
\hline & $\begin{array}{r}\text { Condição } \\
\text { Inicial }\end{array}$ & $\begin{array}{r}\text { Distribuição } \\
\text { de renda }\end{array}$ & $\begin{array}{r}\text { Diversificação } \\
\text { da produção } \\
\text { local }\end{array}$ \\
\hline População & 1629 & 1629 & 1629 \\
Produto Total & 18.100 .000 & 18.211 .166 & 18.997 .937 \\
Gastos Públicos & 4.050 .000 & 4.050 .000 & 4.050 .000 \\
Investimentos & 537.606 & 540.908 & 564.277 \\
Exportações & 12.170 .000 & 12.170 .000 & 12.170 .000 \\
Impostos & 930.000 & 935.712 & 976.137 \\
Consumo total & 12.654 .285 & 12.732 .005 & 13.282 .062 \\
Consumo local & 4.027 .182 & 4.350 .775 & 6.640 .981 \\
Consumo local em relação ao total & $31,82 \%$ & $34,17 \%$ & $50,00 \%$ \\
Consumo total por pessoa & 7.768 & 7.816 & 8.154 \\
\hline
\end{tabular}


Agricultura, população e dinâmica macroeconômica de municípios rurais: um estudo em Lagoa dos Três Cantos (RS)

Tabela 5. Continuação.

\begin{tabular}{lrrr}
\hline & $\begin{array}{r}\text { Condição } \\
\text { Inicial }\end{array}$ & $\begin{array}{r}\text { Distribuição } \\
\text { de renda }\end{array}$ & $\begin{array}{r}\text { Diversificação } \\
\text { da produção } \\
\text { local }\end{array}$ \\
\hline Consumo local por pessoa & 2.472 & 2.671 & 4.077 \\
Coeficiente distribuição de renda & 3,89672769 & 4,19131159 & 3,89672769 \\
Coef. tipo de bens produzidos & 0,72034757 & 0,72034757 & 0,772013606 \\
Poupança & 4.515 .715 & 4.543 .449 & 4.739 .738 \\
Importações de bens de produção & 2.684 .788 & 2.900 .517 & 4.427 .321 \\
Importações de bens de consumo & 8.627 .104 & 8.381 .230 & 6.641 .081 \\
Importação total & 11.311 .892 & 11.281 .747 & 11.068 .401 \\
Saldo da balança comercial & 858.108 & 888.253 & 1.101 .599 \\
Saldo das contas públicas & 3.120 .000 & 3.114 .288 & 3.073 .863 \\
Saldo da conta de capital & 3.978 .108 & 4.002 .541 & 4.175 .462 \\
Balanço global & 0,00 & 0,00 & 0,00 \\
Coeficiente global de importações & 0,62496638 & 0,61949612 & 0,5826107 \\
Multiplicador & 1,08010654 & 1,08652624 & 1,131888935 \\
\hline
\end{tabular}

Fonte: Simulação com dados de pesquisa.

\section{Conclusões}

A partir dos resultados obtidos neste trabalho, concluiu-se que o simples aumento da produção agrícola destinada ao exterior do município teria um efeito limitado no desenvolvimento de atividades não-agrícolas voltadas para o consumo local em Lagoa dos Três Cantos (Rio Grande do Sul). Além disso, a dinâmica demográfica tem uma influência não-linear sobre a demanda de produtos destinados ao consumo local. Assim, uma diminuição da população do município pode facilmente neutralizar os efeitos positivos sobre a renda induzida provocados por um aumento da produção agrícola. Em relação à distribuição de renda, os resultados indicam que uma maior equidade provocaria um aumento importante da demanda por produtos destinados ao consumo local, apesar do efeito limitado que a mesma teria sobre a renda e o consumo totais. Enfim, uma diversificação da produção local que permitisse uma maior participação do consumo doméstico de bens e serviços nos gastos totais em consumo da população teria conseqüências benéficas sobre a renda do município.

De maneira geral, os resultados mostram que Lagoa dos Três Cantos apresenta um desenvolvimento de atividades não-agrícolas bem abaixo do que seria possível a partir do ingresso de moeda proporcionado pela sua produção agrícola e pelos recursos públicos estaduais e federais. Tal "subdesenvolvimento" das atividades não-agrícolas do município, aliado a um desenvolvimento excludente da sua 
agricultura (FIGUEIREDO, 2005), provavelmente está na origem da diminuição da sua população, constatada no último censo (IBGE, 2000), apesar da melhoria dos seus índices de desenvolvimento humano (IPEA, 2003). Diante desse quadro, políticas públicas voltadas ao desenvolvimento de atividades não-agrícolas podem se mostrar decisivas para o futuro de municípios como Lagoa dos Três Cantos. Tais políticas poderiam incluir medidas de estímulos direto e indireto a atividades não-agrícolas. Entre as medidas de apoio direto cita-se a disponibilidade de crédito a juros baixos para financiar a necessidade de capital circulante das atividades comerciais e de serviços. Em relação a medidas de apoio indireto a atividades não-agrícolas, destacam-se aquelas destinadas a evitar a queda da população desses municípios por meio do apoio à reconversão dos sistemas de produção com baixo desempenho econômico, de forma que os agricultores que deles dependem possam se manter na agricultura.

\section{Referências Bibliográficas}

BRUE, S. e McCONNEL, CAMPBELL R., Macroeconomia Princípios, Problemas e Políticas. 14ª ed. São Paulo. Editora LCT, 2001

BUSSARD, J.-M., Economie de 1'Agriculture. Paris. Ed. Économica, 1987

CALlEGARO, S. S., Agricultura, Demanda Agregada e Desenvolvimento em Municípios Rurais: um Estudo de Caso em Coronel Barros (RS). Dissertação de Mestrado apresentada ao Programa de Pós-Graduação em Desenvolvimento, Gestão e Cidadania da Universidade Regional do Noroeste do Estado do Rio Grande do Sul. Ijuí, UNIJUI, 2004 (Documento não publicado).

FIGUEIREDO, J. W., Modelagem Matemática da Dinâmica Macroeconômica de um Município Rural: Um Estudo de Caso em Lagoa dos Três Cantos (RS). Dissertação de Mestrado apresentada ao Programa de Pós-Graduação em Modelagem Matemática da Universidade Regional do Noroeste do Estado do Rio Grande do Sul. Ijuí, UNIJUI, 2005 (Documento não Publicado).

GRAZIANO DA SILVA, J., Políticas não-agrícolas para o novo rural brasileiro. In Ornas. Ocupações Rurais Não-agrícolas: oficina de atualização temática. Londrina, IAPAR, 2000.

INSTITUTO BRASILEIRO DE GEOGRAFIA E ESTATÍSTICA - IBGE, Censo Demográfico de 2000. Brasília. Instituto Brasileiro de Geografia e Estatística, 2000.

INSTITUTO DE POLÍTICAS PÚBLICAS - IPD, Banco de Dados. Ijuí, Disponível em: <http://ipd.unijui.tche.br>. Acesso em: 10 de janeiro de 2006. 
INSTITUTO DE PESQUISA ECONÔMICA APLICADA - IPEA, Atlas de Desenvolvimento Humano no Brasil. Rio de Janeiro, 2003, Disponível em: $<$ http://www.ipea.gov.br/Destaques/destaque.php?num=50>. Acesso: 13 de setembro de 2004).

JARDIM, M. de L. T., Um século de população no Rio Grande do Sul. Porto Alegre, Fundação de Economia e Estatística Siegfried Emanuel Heuser, 2001 (CD-ROOM).

KALECKI, M. Teoria da dinâmica econômica: Ensaios sobre as mudanças cíclicas e a longo prazo da economia capitalista. São Paulo. Ed. Abril Cultural, 1983.

KEYNES, J. M., A teoria geral do emprego, do juro e da moeda. São Paulo: Atlas, 1982.

MAZOYER, M., ROUDART, L., História das Agriculturas do Mundo. Do Neolítico à crise contemporânea. Lisboa. Instituto Piaget, 2001.

Microsoft Inc., Manual do Excel, Microsoft, 1998.

MOUNIER, A., Les théories économiques de la croissance agricole. Paris. INRA/Economica, 1992.

SANTOS, A. M. S. P., Descentralização e autonomia financeira municipal: a perspectiva das cidades médias. Indicadores Econômicos FEE. Porto Alegre. Vol. 32, No. 3, 2004, pág. 101-126.

SILVA NETO, B. e BASSO, D., (Org). Sistemas Agrários do Rio Grande do Sul: análise e recomendações de políticas. Ijuí/RS: Editora UNIJUÍ, 2005.

SILVA NETO, B. e FRANTZ, T. R., A Dinâmica da Agricultura e o Desenvolvimento Rural no Rio Grande do Sul. Brasília, Revista de Economia e Sociologia Rural, Vol. 41, No. 3, Jul.-Set. 2003, pag. 253-272.

SOUZA, N. de J., Desenvolvimento Econômico. 4a ed. São Paulo: Atlas, 1999.

STEVENSON, Willian J. Estatística Aplicada à Administração. São Paulo: Harbra, 1981. 